\title{
Tracheal glomus tumor
}

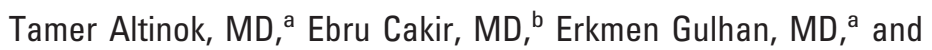

Irfan Tastepe, MD, a Ankara, Turkey

$\mathrm{T}$

he majority of glomus tumors occur in the dermis or subcutis of the extremities. It is extremely rare in the tracheobronchial tree: only 16 cases have been reported in the literature. ${ }^{1}$ Although glomus tumors are predominantly benign, they rarely demonstrate an aggressive and malignant clinical course and histologic characteristics. Herein we discuss a patient with a tracheal glomus tumor classified as "uncertain malignant potential" according to the new World Health Organization (WHO) classification.

\section{Clinical Summary}

An 83-year-old woman presenting with hemoptysis and dyspnea was admitted to our hospital. She had a 3-month history of cough and progressive dyspnea. The results of chest roentgenography

From the Departments of Thoracic Surgery ${ }^{\mathrm{a}}$ and Pathology, ${ }^{\mathrm{b}}$ Atatürk Center For Chest Disease and Thoracic Surgery, Ankara, Turkey.

Received for publication Feb 2, 2006; revisions received March 15, 2006; accepted for publication March 21, 2006

Address for reprints: Tamer Altinok, MD, Sehit Mustafa Bas Cad, 79/4, 06130 Aydinlikevler-Ankara, Turkey (E-mail: taltinoks@yahoo.com).

J Thorac Cardiovasc Surg 2006;132:201-2

$0022-5223 / \$ 32.00$

Copyright () 2006 by The American Association for Thoracic Surgery doi:10.1016/j.jtcvs.2006.03.032 were normal. On physical examination, she had cyanosis and inspiratory-expiratory wheezing. Pulmonary function tests showed a forced vital capacity of $0.4 \mathrm{~L}(27 \%)$ and a forced expiratory volume in 1 second/forced vital capacity ratio of $73 \%$. Arterial blood gas analysis on room air breathing showed a $\mathrm{PO}_{2}$ of $40.1 \mathrm{~mm} \mathrm{Hg}$, a $\mathrm{PCO}_{2}$ of $42.7 \mathrm{~mm} \mathrm{Hg}$, and a $\mathrm{pH}$ of 7.41 , and oxygen saturation was $75.6 \%$. A thorax computed tomographic scan revealed a $1-\mathrm{cm}$ polypoid soft tissue lesion arising from the posterolateral wall and occupying $80 \%$ of the lumen of the upper third of the trachea (Figure 1). Rigid bronchoscopy showed a mobile polypoid mass arising from the right posterolateral tracheal wall $5 \mathrm{~cm}$ below the vocal cord, occupying $80 \%$ of the tracheal lumen. Through a right minithoracotomy, the lesion, palpated above the azygos vein, was resected with its peduncle by means of partial sleeve resection. The trachea was repaired primarily with nonabsorbable sutures (Figure 1).

The surgical specimen was a sessile, solid polypoid tumor of $2.0 \times 1.5 \times 1.2 \mathrm{~cm}$. Microscopically, the tumor was composed of sheets and trabeculae of round to polygonal cells with eosinophilic cytoplasm and indistinct cell borders interspersed with varioussized vessels. At the periphery of the mass, the cytologic features of the tumor cells resembled benign glomus tumor. At the center of the mass, the neoplastic cells exhibited moderate nuclear atypia and increased mitotic activity (4 mitoses per 50 high-power fields,

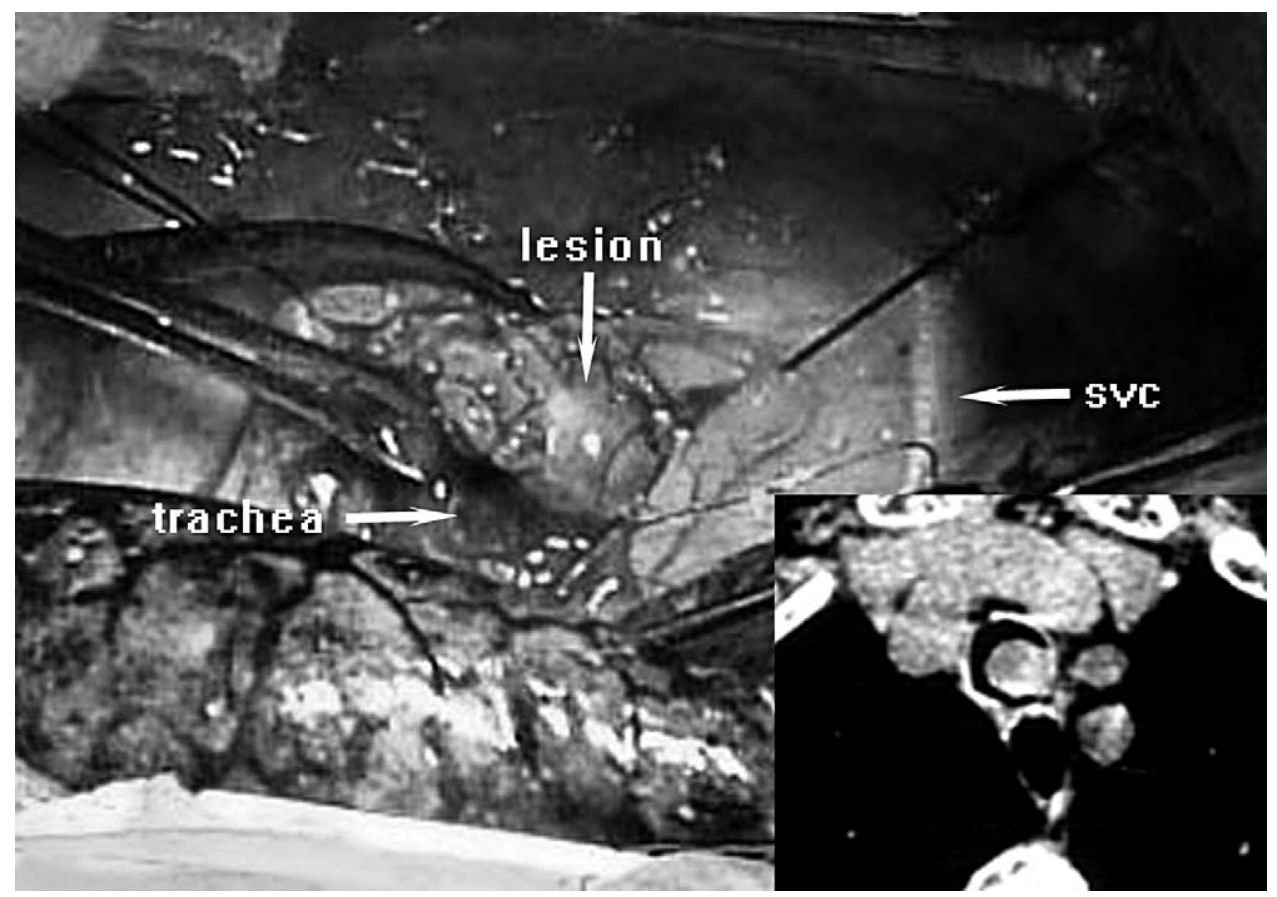

Figure 1. Thorax computed tomographic scan revealed a $1-\mathrm{cm}$ polypoid soft tissue lesion occupying the lumen of the trachea. Intraoperative view of the endotracheal lesion. SVC, superior vena cava. 


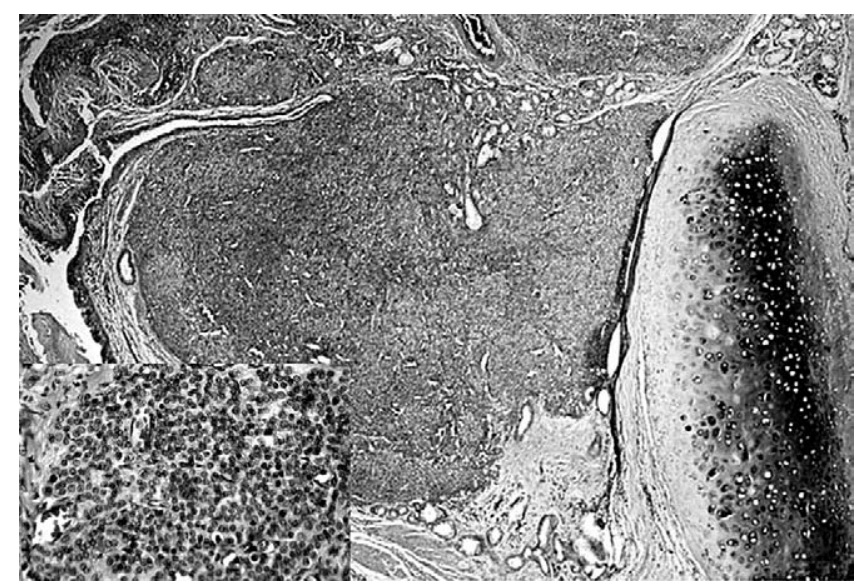

Figure 2. Tracheal tumor infiltrating the subepithelial glandular structures (hematoxylin and eosin, original magnification $40 \times$ ) and moderate nuclear atypia and increased mitotic activity (hematoxylin and eosin, original magnification $400 \times$ ).

Figure 2). There was no necrosis, atypical mitotic figure, or vascular space involvement. The tumor cells were immunoreactive with $\alpha$-smooth muscle actin and vimentin but were negative with S-100 protein, pancytokeratin, epithelial membrane antigen (EMA), CD34, desmin, chromogranin, and neuron-specific enolase (NSE). On the fifth postoperative day, the patient was dismissed from the hospital without any complications. She was asymptomatic for 12 months after the operation.

\section{Discussion}

Glomus tumors, known as benign tumors, first described by Mason in 1924, typically involve the skin of the hand and especially the subungual region of the finger. They are extremely rare in the trachea.

The benign form accounts for more than $95 \%$ of these lesions. Folpe and colleagues ${ }^{2}$ proposed a new classification of atypical and malignant glomus tumors after survey of 52 unusual glomus tumors. According to the new WHO classification of glomus tumors based on the study of Folpe and colleagues, ${ }^{3}$ glomus tumors with atypical features are divided into 4 categories: malignant glomus tumor, glomus tumor with nuclear atypia only, glomus tumor of uncertain malignant potential, and glomangiomatosis. It is men- tioned that the diagnosis of malignant glomus tumor should be reserved for tumors showing (1) size of greater than $2 \mathrm{~cm}$ and subfascial or visceral location, (2) atypical mitotic figures, or (3) marked nuclear atypia and any level of mitotic activity, and also glomus tumors not fulfilling criteria for malignancy but having at least one atypical feature other than nuclear pleomorphism should be diagnosed as a "glomus tumor of uncertain malignant potential." 3

The tumor presented here has characteristic features of a benign-appearing typical glomus tumor at the periphery of the mass (and this is the most important clue for the diagnosis ${ }^{2}$ ) but also has some atypical histomorphologic features (eg, moderate nuclear atypia), mitotic activity, and unusual clinical features (eg, deep location). These criteria do not meet the minimum definition of malignant glomus tumor according to the new WHO classification but are consistent with the diagnosis of glomus tumor of uncertain malign potential.

The diagnosis of tracheobronchial glomus tumors can be elusive. It is necessary to differentiate from carcinoid tumors and hemangiopericytomas. ${ }^{4}$ Immunohistochemically, smooth muscle actin expression and abundant pericellular type 4 collagen production confirm the diagnosis of glomus tumor. ${ }^{3}$

Folpe and colleagues ${ }^{2}$ mention that none of their patients in this category experienced an adverse event, but this label will evoke close follow-up care. Sleeve resection with primary reconstruction is the treatment of choice for glomus tumors. Bronchoscopic tracheal stenting or laser resection with or without adjuvant radiotherapy should be reserved for patients with inoperable tumors. ${ }^{5}$ Complete surgical resection is curative and requires no further treatment.

\section{References}

1. Nadrous HF, Allen MS, Bartholmal BJ, et al. Glomus tumor of the trachea: value of multidetector computed tomographic virtual bronchoscopy. Mayo Clin Proc. 2004;79:237-40.

2. Folpe AL, Fanburg-Smith JC, Miettinen M, et al. Atypical and malignant glomus tumors: analysis of 52 cases, with a proposal for the reclassification of glomus tumors. Am J Surg Pathol. 2001;25:1-12.

3. Folpe AL. Glomus tumors. In: Fletcher CDM, Unni KK, Mertens F, editors. World Health Organisation classification of tumors: pathology and genetics of tumors of soft tissue and bone. Lyon (France): IARC Press; 2002. p. 136-7.

4. Lange TH, Magee MJ, Boley TM, et al. Tracheobronchial glomus tumor. Ann Thorac Surg. 2000;70:292-5.

5. Arapantoni-Dadioti P, Panayiotides J, Fatsis M, Antypas G. Tracheal glomus tumour. Respiration. 1995;62:160-2. 